\title{
Speaking up: a model of self-advocacy for STEM undergraduates with ADHD and/or specific learning disabilities
}

\author{
Mariel A. Pfeifer ${ }^{1}$, Eve Melanie Reiter ${ }^{2}$, McKenna Hendrickson $^{3}$ and Julie Dangremond Stanton ${ }^{2^{*}}$ (D)
}

\begin{abstract}
Background: Students with disabilities are underrepresented in undergraduate science, technology, engineering, and mathematics (STEM) courses. Students with disabilities who engage in self-advocacy earn higher GPAs and are more likely to graduate from college compared to students with disabilities who do not engage in self-advocacy. We utilized Test's conceptual framework of self-advocacy, which breaks self-advocacy into four components: knowledge of self, knowledge of rights, communication, and leadership to investigate how students with invisible disabilities practice self-advocacy in undergraduate STEM courses. Through a partnership with a disability resource center (DRC), we recruited and interviewed 25 STEM majors who received accommodations for attention-deficit/ hyperactivity disorder (ADHD) and/or a specific learning disorder (SLD). Data were collected using semi-structured interviews and analyzed using content analysis.

Results: We found evidence of all components of Test's conceptual framework of self-advocacy and operationalize each based on our participants' experiences. We identified novel components of self-advocacy for students with ADHD/SLD in undergraduate STEM courses, including knowledge of STEM learning contexts and knowledge of accommodations and the process to obtain them, as well as, a novel self-advocacy behavior, filling gaps. Filling gaps involved participants taking action to mitigate a perceived limitation in either their formal accommodations from the DRC or a perceived limitation in the instructional practices used in a STEM course. We also identified beliefs, such as view of disability and agency, which influenced the self-advocacy of our participants. We incorporated the emergent forms of self-advocacy into Test's conceptual framework to propose a revised model of self-advocacy for students with ADHD/SLD in undergraduate STEM courses.

Conclusions: We developed a revised conceptual model of self-advocacy for students with ADHD/SLD in undergraduate STEM courses. This conceptual model provides a foundation for researchers who wish to study selfadvocacy in undergraduate STEM courses for students with ADHD/SLD in the future. It also offers insights for STEM instructors and service providers about the self-advocacy experiences of students with ADHD/SLD in undergraduate STEM courses. We propose hypotheses for additional study based on our conceptual model of self-advocacy. Implications for research and teaching are discussed.
\end{abstract}

Keywords: Students with ADHD, Students with SLD, Attention-deficit/hyperactivity disorder, Specific learning disorder, Specific learning disability, Invisible disability, Hidden disability, Self-advocacy, Undergraduate STEM courses

\footnotetext{
* Correspondence: stantonj@uga.edu

²Department of Cellular Biology, University of Georgia, Athens, GA 30602,

USA

Full list of author information is available at the end of the article
} 


\section{Introduction \\ Background}

Students with disabilities are underrepresented in science, technology, engineering, and mathematics (STEM) majors and this underrepresentation of individuals with disabilities persists in STEM workforce settings (National Science Foundation, 2019). In college, students with disabilities encounter many challenges influencing their retention in STEM majors (Carabajal, Marshall, \& Atchison, 2017; Dunn, Rabren, Taylor, \& Dotson, 2012; Hong, 2015). One important challenge students with disabilities in the US face during college is a shift in legislation guiding the accommodation process (Hadley, 2007; Janiga \& Costenbader, 2002). In public high schools, accommodations are guaranteed primarily through an educational law called the Individuals with Disabilities Education Act (IDEA) (Smith, 2001). Under IDEA, public schools are responsible for identifying and accommodating students with disabilities. As students with disabilities matriculate into college, IDEA no longer applies. In college, civil rights legislation, specifically the Americans with Disabilities Act (ADA) and its amendments, work in tandem with Section 504 of the Rehabilitation Act of $1973^{1}$ to ensure access to accommodations (Eckes \& Ochoa, 2005; Smith, 2001). The ADA calls colleges and universities to provide "reasonable accommodations" that do not "fundamentally alter" the nature of the academic program (Americans with Disabilities Act of, 1990). Importantly, in college, students themselves become solely responsible for seeking and managing their own accommodations (Hadley, 2007; Janiga \& Costenbader, 2002). Thus, as students with disabilities begin college, many are learning not only how to navigate life as a college student, but also how to navigate the academic accommodation process on their own for the first time. Successful navigation of the accommodation process in college requires self-advocacy (Hadley, 2007).

\section{Self-advocacy for students with disabilities}

Self-advocacy for students with disabilities has been defined and conceptualized in many ways ${ }^{2}$ (Gelbar et al., 2019; Test et al., 2005). One well-accepted definition of self-advocacy is the "ability to assertively state wants, needs and rights, determine and pursue needed

\footnotetext{
${ }^{1}$ Section 504 of the Rehabilitation Act of 1973 applies to students with disabilities in public and private high schools (Taylor, 2005). No existing research examines if there are differences in the self-advocacy experiences of students who attend public or private high school. We hypothesize that self-advocacy is an essential skill for any student, regardless of whether they attend a public or private high school. ${ }^{2}$ Self-advocacy has been conceptualized as an educational goal, a political movement, and as a component of the broader theoretical framework self-determination for students with disabilities (Gelbar et al., 2019; Test, Fowler, Wood, Brewer, \& Eddy, 2005; Ward \& Meyer, 1999; Wehmeyer, Abery, Mithaug, \& Stancliffe, 2003).
}

supports, and conduct your own affairs" (Izzo \& Lamb, 2002, p. 6). In studies of students with disabilities, selfadvocacy emerged as a critical factor related to the success and retention of students with disabilities in college (e.g., Kinney \& Eakman, 2017; Lombardi, Gerdes, \& Murray, 2011). While self-advocacy is identified as an important skill that can be taught to students with disabilities, it is less clear how students with disabilities practice self-advocacy in the context of their undergraduate courses (Holzberg, Test, \& Rusher, 2019; A. R. Walker \& Test, 2011). Few studies describe how students with disabilities practice self-advocacy in their day-to-day lives as college students, and little research exists investigating how students with disabilities practice self-advocacy in undergraduate STEM courses.

\section{A conceptual framework for self-advocacy for individuals with disabilities}

Fortunately, a conceptual framework of self-advocacy exists. Test et al. (2005) generated a conceptual framework of self-advocacy through a meta-analysis of 20 research studies of individuals with disabilities, along with input from stakeholders. Stakeholder feedback on working drafts of Test's conceptual framework consisted of responses from seven individuals, including two adults with disabilities known to be active self-advocates, three researchers in the field, and two adult self-advocacy training organizations. In this conceptual framework, self-advocacy contains four components: knowledge of self, knowledge of rights, communication, and leadership (Test et al., 2005). Knowledge of self is awareness of one's own strengths and weaknesses as a student and as an individual with a disability. Knowledge of rights is awareness of relevant federal laws and policies that govern the accommodation process for college students with disabilities. Communication entails behaviors that ensure successful communication about accommodations. An example of successful communication involves engaging in assertive, yet not aggressive, communication with instructors and service providers regarding accommodations and accommodation-related issues. Notably, knowledge of self, knowledge of rights, and communication are considered to be essential for self-advocacy in Test's conceptual framework, whereas leadership is not considered to be essential for self-advocacy. Leadership is broadly defined in Test's conceptual framework and encompasses many subcomponents, ranging from an awareness of individual roles and responsibilities within a group during accommodation meetings to taking political action on behalf of other people with disabilities.

The research that informed development of Test's conceptual framework of self-advocacy involved studies of individuals that ranged greatly in terms of age, disability type, and context (Test et al., 2005). While development 
of the conceptual framework represented a key step in the delineation of self-advocacy from the broader theoretical framework of self-determination, few, if any subsequent studies, have empirically tested if and how Test's conceptual framework of self-advocacy applies to subpopulations of individuals with disabilities. For example, the lived experiences of a college student with an apparent disability, such as a visual impairment, can be much different than the lived experiences of a college student with an invisible or hidden disability, such as attention-deficit/hyperactivity disorder (ADHD) (Daly-Cano, Vaccaro, \& Newman, 2015; Vaccaro, Kimball, Wells, \& Ostiguy, 2015). Given the importance of self-advocacy in the success and retention of students with disabilities in college, we sought to understand how Test's conceptual framework of self-advocacy applied to STEM majors with disabilities.

\section{Self-advocacy in the context of undergraduate STEM}

Although self-advocacy is recognized as a critical determinant in academic success for students with disabilities, very few, if any, existing studies examine how students with disabilities engage in self-advocacy within specific academic disciplines (Fleming, Plotner, \& Oertle, 2017; Holzberg et al., 2019; Kinney \& Eakman, 2017; Lombardi et al., 2011). Within higher education research, studies about students with disabilities are uncommon (Peña, 2014). Similarly, studies about students with disabilities are uncommon within undergraduate STEM education research (e.g. Schreffler, Vasquez Iii, Chini, \& James, 2019; Thurston, Shuman, Middendorf, \& Johnson, 2017). Students with disabilities encounter unique challenges in undergraduate STEM courses (Moon, Todd, Morton, \& Ivey, 2012). For example, the use of ambiguous language in chemistry and other STEM contexts can impede learning for students with certain types of disabilities (Isaacson \& Michaels, 2015). Students with disabilities in STEM are less likely than their counterparts in other academic disciplines to use accommodations in their courses (Lee, 2011; Lee, 2014). The reasons fewer students with disabilities in undergraduate STEM courses use accommodations are not well characterized. We hypothesize this phenomenon is related to selfadvocacy. We sought to study self-advocacy in the context of undergraduate STEM courses to define what encompasses self-advocacy for students with disabilities in this academic context. We were particularly interested in how students with two types of invisible disabilities ${ }^{3}$, ADHD and specific learning disorders, also called specific learning disabilities (SLD), practiced self-advocacy.

\footnotetext{
${ }^{3}$ We elected to use the term disability throughout our study because this was the term most familiar to our participants. However, other terms such as impairment or learning difference may be the preferred term for some individuals.
}

We were interested in how students with ADHD/SLD practice self-advocacy because the invisible, or nonapparent, nature of these disabilities requires students to disclose their disability status in order to receive accommodations. For instance, a STEM instructor would not necessarily be able to tell based on a student's outward appearance if they had a disability or if they needed accommodations in a course, whereas a student with an apparent disability may be more readily identified as an individual who may need accommodations in a course. In the following section, we explain the rationale for our decision to aggregate multiple disability types into one study by defining ADHD, SLD, and briefly outline documented similarities and differences between students with ADHD/SLD (Vaccaro et al., 2015).

\section{ADHD and SLD}

Two of the most commonly occurring invisible disabilities on college campuses are ADHD and SLD (Raue \& Lewis, 2011). Both ADHD and SLD are examples of neurodevelopmental disorders (American Psychology Association, 2013). ADHD is comprised of two major subtypes: predominantly inattentive and predominantly hyperactive/impulsive. The inattentive form of ADHD is characterized by challenges in maintaining focus in dayto-day life and may manifest when individuals with ADHD overlook details, do not listen when spoken to directly, or do not follow through on instructions. Individuals with the inattentive form of ADHD may also experience challenges in organizing tasks and activities or be easily distracted by outside stimuli and unrelated thoughts. Individuals diagnosed with the hyperactive/impulsive subtype of ADHD can be described as "on the go" (American Psychiatric Association, 2013). They may experience intense feelings of restlessness that can be evident in fidgeting, excessive talking, difficulty in waiting for turns, and interrupting or intruding upon others.

SLD are divided into three major subtypes: impairment in reading (dyslexia), impairment in written expression (dysgraphia), and impairment in mathematics (dyscalculia) (American Psychiatric Association, 2013). SLD can be identified when an individual experiences difficulty in learning and using academic skills, such as reading comprehension, spelling, written expression, number sense, number facts, calculation, and mathematical reasoning. A key determinant of SLD is that the academic skill affected by an SLD is substantially below the expected level given the chronological age of the individual. Typically, SLD are diagnosed at a young age, but an individual may be diagnosed with an SLD later in life when they experience increased academic rigor.

Students with ADHD and students with SLD are often studied together because of their prevalence in college students and because these conditions often co-occur at 
a rate of 31-45\% (DuPaul, Gormley, \& Laracy, 2013; Pham \& Riviere, 2015; Raue \& Lewis, 2011; Wolf, 2001). SLD and ADHD also share cognitive factors such as impaired processing speed and working memory (Budd, Fichten, Jorgensen, Havel, \& Flanagan, 2016; Costello \& Stone, 2012). Additionally, students with ADHD and students with SLD tend to show similar disparities compared to students without disabilities in terms of motivation, anxiety, information processing, and monitoring understanding (Reaser, Prevatt, Petscher, \& Proctor, 2007). Despite commonalities between students with ADHD and students with SLD, researchers have documented very few differences between students with ADHD and students with SLD. For example, one study found that students with only ADHD self-report lower grades and lower course-related self-efficacy than students with only SLD, but higher confidence to read textbooks compared to students with only SLD (Budd et al., 2016). Although differences between students with ADHD and SLD exist, we found that including both disability types in one study was appropriate considering the purpose of our study was to investigate self-advocacy in students with two common invisible disabilities on college campuses (Vaccaro et al., 2015).

\section{Guiding theoretical framework}

We are broadly guided by the social model of disability. The social model of disability distinguishes impairment from disability (Berghs, Atkin, Graham, Hatton, \& Thomas, 2016; Haegele \& Hodge, 2016). Impairments are biological differences, and disability is the hardship an individual with an impairment experiences due to societal expectations (Berghs et al., 2016; Haegele \& Hodge, 2016). For example, blindness resulting from macular degeneration is a form of visual impairment. If we consider an individual with a visual impairment in an elevator without Braille numbers on the call buttons navigating to a specific floor, we would say that the individual has a biological difference, their visual impairment, but they are not disabled because of their impairment. Instead, they are disabled because the elevator was not designed for people with visual impairments.
From the social model standpoint, disabilities are addressed through political and social change (Berghs et al., 2016; Haegele \& Hodge, 2016). For example, disability could be addressed by adopting policy mandating all call buttons include corresponding Braille numbers. The social model of disability prompts individuals to enact political and social change to address disability, and this notion translates into educational contexts. We find the social model of disability is appropriate for our study because it calls individuals with impairments to take action to improve their own conditions within society. We consider self-advocacy to be the construct that empowers individuals to take these types of actions. For instance, STEM majors with ADHD/SLD can practice selfadvocacy to ensure access to academic accommodations, which may improve their own condition within a microcosm of society, the undergraduate STEM classroom.

The purpose of our study is to characterize the selfadvocacy experiences of students with ADHD/SLD in undergraduate students. We utilized Test's conceptual framework of self-advocacy (Test et al., 2005) that outlined four components of self-advocacy (Fig. 1) to begin addressing our primary research question. We asked: What components of self-advocacy are evident in students with ADHD/SLD in undergraduate STEM courses?

\section{Methods \\ Context of study}

We conducted our study at a large public university with the highest research activity in the southeastern USA. This study was approved for exempt status by the University of Georgia Institutional Review Board (STUDY00004663) and is part of a larger study of students with ADHD and SLD in undergraduate STEM courses. All participants in the study were registered with the campus Disability Resource Center (DRC) and all participants were STEM majors. Most of the participants were actively using academic accommodations at the time of the study. However, one participant had not used accommodations for several semesters, and one participant had never formally used accommodations in college.

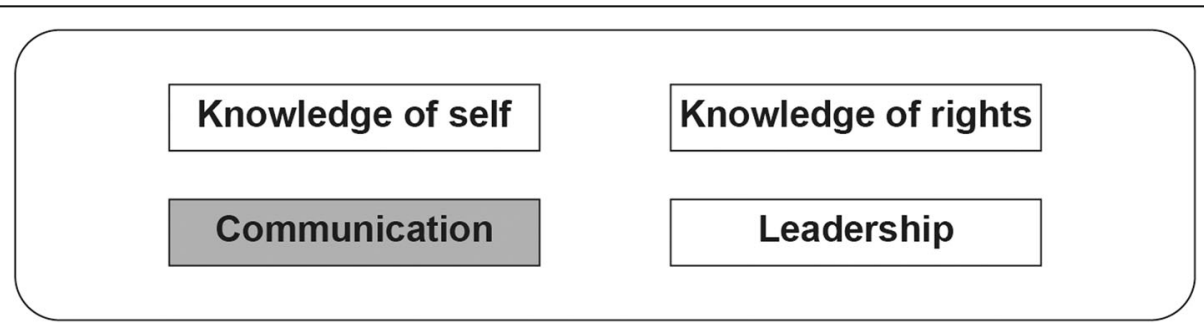

Fig. 1 Test's conceptual model of self-advocacy (Test et al., 2005). Knowledge of self and knowledge of rights are foundational, communication is described as essential (shaded box), and leadership is seen as non-essential for self-advocacy. We refer to these components of self-advocacy as "Test's components" or "original components" of self-advocacy 


\section{Participant identification and recruitment}

We established a partnership with our institution's Disability Resource Center (DRC) to recruit students currently registered to receive academic accommodations. Our partners at the DRC distributed a recruitment email to all students meeting the criteria of the study to ensure confidentiality of registered students. Our recruitment method also preserved student confidentiality because only those students interested in participating in the research study contacted us. Eligibility requirements included that the participant must (1) be currently registered with the DRC and eligible to receive accommodations for either ADHD or SLD as a primary or secondary condition and (2) have completed at least one course which fulfilled the science and quantitative reasoning core curriculum requirement. A round of recruitment emails was sent by our DRC partner to all eligible students in Fall 2018 and again in Spring 2019. Our recruitment email included standard recruitment language and a video with closed-captions to provide multiple means of representation to our potential participants (CAST, 2020). In Spring 2019, we also advertised the study by hanging flyers at the DRC with our contact information. Students interested in participating in the study were invited to contact us directly.

Once initial contact with potential participants was established, we sent a brief screening survey to the student to ensure that each participant had completed at least one undergraduate STEM course at the institution where data collection took place. We then invited participants to schedule an interview at their convenience. Participation was incentivized by providing $\$ 20$ cash for completion of one interview. We recruited 13 participants in Fall 2018 and 12 participants in Spring 2019. All participants provided written informed consent.

\section{Development of the interview protocol}

We conducted semi-structured interviews to characterize the self-advocacy experiences of students with ADHD and/or specific learning disabilities (SLD) in undergraduate STEM courses. Semi-structured interviews utilize a formal interview protocol, but researchers are able to ask follow-up questions as needed to elicit rich detail from participants. Development of our interview protocol was informed by Test's framework of self-advocacy (Test et al., 2005), along with other previous research regarding the experiences of students with learning disabilities and ADHD in college (e.g., Hadley, 2007). An initial interview protocol was piloted with three students with SLD and one student with a traumatic brain injury. Refinements to the wording and order of interview questions were made based on the results of the pilot study and feedback from our DRC partners. The final interview protocol contained two major sections. The first section was designed to characterize the self-advocacy experiences of students with ADHD/SLD in undergraduate STEM courses and the second section was designed to explore the role active learning in undergraduate STEM courses plays on selfadvocacy, the results of which will be published separately. Interview questions related to the current study are available in Supplementary Table 1.

\section{Data collection and survey}

One researcher interviewed all 25 participants using the final interview protocol. The average length of an interview was $80 \mathrm{~min}$. At the end of each interview, participants completed a short demographic survey. Demographic information of our participants is summarized in Table 1. Each interview was audio-recorded. Immediately following each interview, the interviewer wrote analytic memos regarding overall impressions of self-advocacy for each participant. All interviews were professionally transcribed. Transcripts were checked to ensure fidelity of the data.

Table 1 Summary of participant $(n=25)$ demographic information

\begin{tabular}{|c|c|c|}
\hline Attribute & & $\begin{array}{l}\text { Number of } \\
\text { participants (\%) }\end{array}$ \\
\hline \multirow[t]{2}{*}{ Gender } & Female & $11(44)$ \\
\hline & Male & $14(56)$ \\
\hline \multirow[t]{2}{*}{ Race } & White & $23(92)$ \\
\hline & Black or African American & $2(8)$ \\
\hline \multirow[t]{5}{*}{ STEM major } & Life sciences & $13(52)$ \\
\hline & Engineering & $7(28)$ \\
\hline & Physical science & $2(8)$ \\
\hline & Mathematics & $2(8)$ \\
\hline & Computer science & $1(4)$ \\
\hline \multirow[t]{6}{*}{ Year in college } & First year & $3(12)$ \\
\hline & Second year & $3(12)$ \\
\hline & Third year & $8(32)$ \\
\hline & Fourth year & $4(16)$ \\
\hline & Fifth year & $5(20)$ \\
\hline & Sixth year + & $2(8)$ \\
\hline \multirow[t]{3}{*}{ Participant diagnoses } & $\mathrm{ADHD}$ & $15(60)$ \\
\hline & $\begin{array}{l}\text { Specific learning } \\
\text { disability (SLD) }\end{array}$ & $5(20)$ \\
\hline & ADHD and SLD & $5(20)$ \\
\hline \multirow[t]{2}{*}{ Age at official diagnosis } & College & $8(32)$ \\
\hline & Before college & $17(68)$ \\
\hline \multirow{2}{*}{$\begin{array}{l}\text { Type of high school } \\
\text { attended }\end{array}$} & Public & $14(56)$ \\
\hline & Private & $11(44)$ \\
\hline \multirow[t]{3}{*}{ Other } & Transfer students & $6(24)$ \\
\hline & First-generation students & $2(8)$ \\
\hline & Pell grant recipients & $5(20)$ \\
\hline
\end{tabular}




\section{Qualitative data analysis}

Data were analyzed by a diverse research team, including at least one or more researchers who were a STEM major with ADHD/SLD, and a researcher who had worked as a DRC coordinator at another institution. We used MaxQDA 2018 (VERBI Software, 2017) for qualitative analysis. We open-coded (sometimes referred to as initial coding) all 25 transcripts (Saldaña, 2015). In our open-coding process, we sought to find nuances in our data and to remain open to emergent ideas related to self-advocacy by reading each transcript. After reading each transcript, members of the research team wrote analytic memos regarding their impressions of the data. Members of the research team met extensively throughout the open-coding process to share thoughts about the data and to discuss ideas and concepts that emerged from the open-coding process.

We developed our codebook using a set of five interviews that represented the range of our data. The first four codes of our codebook were a priori (or deductive or theory-driven), originating from Test's conceptual framework of self-advocacy. These a priori codes were knowledge of self, knowledge of rights, leadership, and communication. We identified relevant segments of interviews that represented these a priori codes.

We relied on a constant comparative method to develop our emergent or inductive codes (Charmaz, 2006; Fram, 2013). This involved three members of the research team proposing codes to each other after reading the same set of interviews. Initially, our research team generated over 100 possible proposed codes. Given the large number of proposed codes, we met to discuss these proposed codes and to come to an agreement on the codes that aligned with our research questions. We sought to refine our proposed codes by reading additional interviews individually and meeting as a research team to add or remove codes and to redefine existing codes as needed. We used the most current iteration of the codebook to code one interview individually and then meet as a research team to discuss how each individual applied the codes. Through this process, our codebook stabilized. Codes related to this study are provided in Supplemental Materials. Using our stabilized codebook, two researchers coded all 25 interviews, meeting after intervals of three to four interviews to discuss coding, and to code to consensus. This involved resolving any coding disagreements by discussing the code and the data until an agreement was reached. Subsequently, a third researcher coded all 25 interviews to give insights as a person who was a STEM major with ADHD/ $\mathrm{SLD}$. One researcher involved in the analysis from the beginning then discussed coding with the third coder. From this iterative process, all first-cycle codes applied were reviewed and approved by at least two members of our research team.
In our analysis, we elected to code to consensus in an effort to attain reliability and validity. In qualitative research, reliability is the dependability of the research, while validity addresses the degree to which the findings are trustworthy and defensible (Golafshani, 2003; Lincoln \& Guba, 1985). Coding to consensus is considered one of the most rigorous analytic strategies by many qualitative researchers, especially when analyzing complex phenomenon, such as self-advocacy, or when using intricate codebooks (Curry, Nembhard, \& Bradley, 2009; Foster, Urquhart, \& Turner, 2008; Morse, 1997; Richards \& Hemphill, 2018). Coding to consensus by a diverse research team brings "richness to data interpretation" (Olson, McAllister, Grinnell, Gehrke Walters, \& Appunn, 2016, p. 30). When coding to consensus, differences between researchers are acknowledged, discussed, and resolved, thereby accounting for diverse viewpoints in the output of the analytic process. Moreover, studies show that calculated measures of interrater reliability may actually function to reduce reliability and validity of a qualitative study in practice (Eisner, 1991; Sandelowski \& Barroso, 2003). In these situations, researchers find themselves making coding decisions in an effort to agree with one another, instead of considering the actuality of the data. In our view, coding to consensus as opposed to calculating a measure of interrater reliability was an appropriate decision given our participants, the construct of self-advocacy, and our study design.

We transitioned to second-cycle coding by conducting axial and pattern coding to identify emergent themes from our analysis. Axial coding involves describing the properties and dimensions of a code and determining how these attributes relate to one another, while pattern coding organizes similarly coded data into themes (Saldaña, 2015). Second-cycle coding was headed by one researcher with input from two additional members of the research team. If disagreements regarding second-cycle codes emerged, we discussed differences until members of the research team agreed. From this process, we identified emergent themes related to self-advocacy of our participants in the context of undergraduate STEM courses. We incorporated these themes into a model that included the four components of Test's conceptual framework.

\section{Trustworthiness of study}

Our study establishes trustworthiness in several ways (Krefting, 1991; Tracy, 2010). We provide transparency in our research by describing our methods in detail. Our study design and interview protocol were reviewed by DRC coordinators and staff with extensive experience working with the target population of our study. We also provide rationalization for aggregating students with ADHD and/or SLD into a single study (Vaccaro et al., 
2015). Furthermore, our interview protocol was piloted and refined based on feedback from students with similar disabilities to our participants. We formed a diverse research team to analyze our data by coding to consensus. Our research team included one or more researchers who were STEM majors with ADHD/SLD, and a researcher who had worked as a DRC coordinator at another institution (Vaccaro et al., 2015).

\section{Results}

Test's conceptual framework of self-advocacy outlined four components of self-advocacy: knowledge of self, knowledge of rights, communication, and leadership (Test et al., 2005; Fig. 1). We first asked: What components of Test's self-advocacy framework are evident in students with ADHD and/or SLD in undergraduate STEM courses? We found evidence of each component of self-advocacy from Test's framework. Besides these components of the framework, we identified emergent components of self-advocacy based on the experiences of our participants. From our analysis, we generated a model of self-advocacy for students with ADHD/SLD in the context of undergraduate STEM courses based on the experiences of our participants (Fig. 2). In the following sections, we describe selfadvocacy knowledge, self-advocacy behaviors, and beliefs influencing self-advocacy. We use headers to differentiate components of Test's framework from the emergent components of our analysis. Although the components sometimes overlapped and intersected within the data, we characterize each self-advocacy component separately for clarity.

Participant quote data were lightly edited for clarity. For example, brackets indicate words we edited for readability, and ellipses represent portions of the interview we excluded for conciseness. All names are pseudonyms.

Overview of accommodation process for our participants One strength of qualitative research is that it allows researchers to develop a detailed understanding of phenomenon situated in a specific context. We provide an

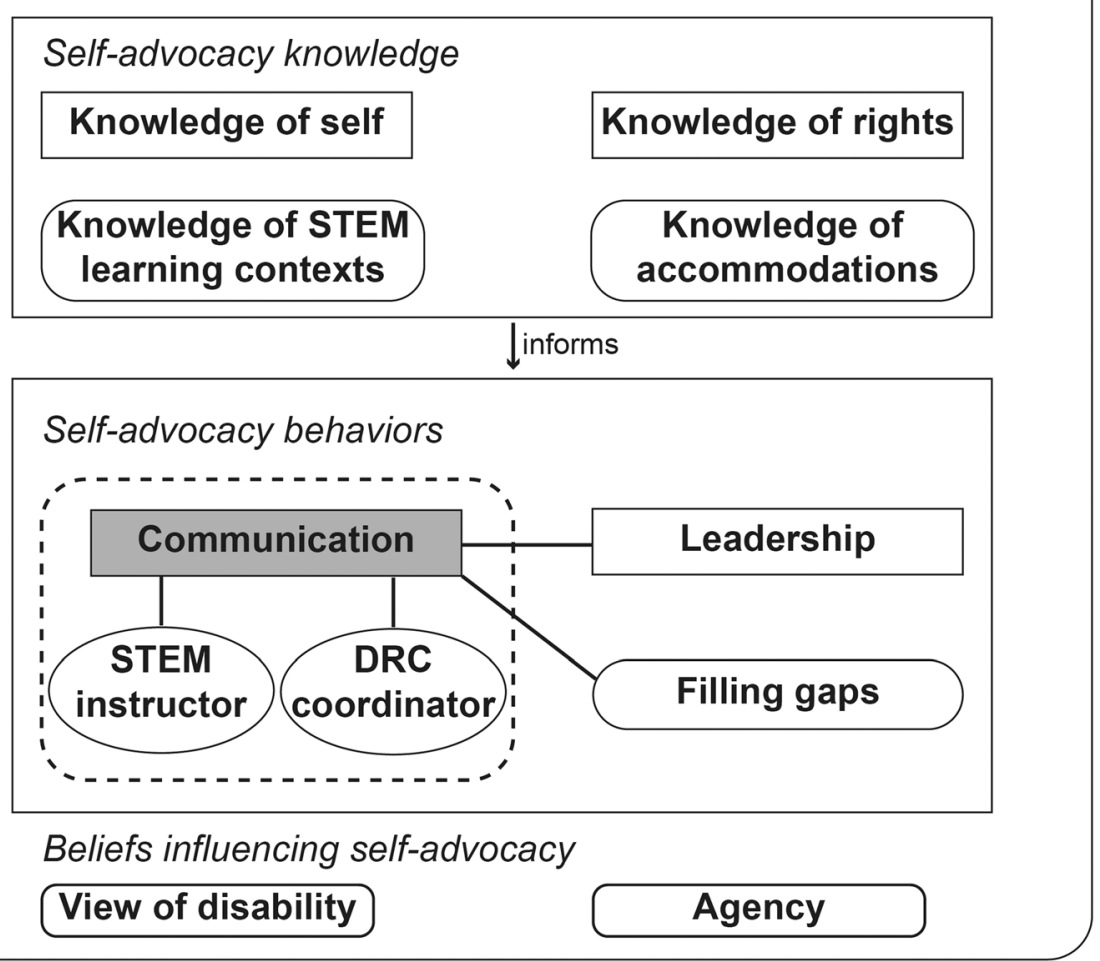

Fig. 2 Proposed model of self-advocacy for students with ADHD and/or SLD in the context of undergraduate STEM courses, based on our participants' experiences. Square-edged boxes represent components of Test's conceptual framework (Test et al., 2005). Rounded-edged boxes represent emergent themes from our qualitative analysis. Ovals represent individuals our participants interacted with to practice self-advocacy. The shaded box represents a required component of self-advocacy. The dashed line box surrounding communication represents communication with STEM instructors and DRC coordinators. Lines connecting communication to leadership and filling gaps represent the integral role of communication in self-advocacy, e.g., communication is required for leadership and filling gaps. Components of self-advocacy can overlap due to their intersecting nature 
overview of the steps involved in the accommodation process for our participants to contextualize their experiences requesting accommodations in their undergraduate STEM courses (Fig. 3). Participants formally register with the campus DRC by providing documentation of their disability. This documentation is reviewed and once it is approved, participants are officially registered with the DRC. Participants are then invited to make an initial accommodation meeting with their assigned DRC coordinator. In this meeting, the participant and their DRC coordinator agree upon what accommodations the participant will request from their instructors for that semester. The formal accommodation letters are then generated in an online accommodation system and sent to the instructors of each course. The accommodation letters disclose the name of the participant and the type of accommodation(s) the participant requests in a course. No additional information about the participant's disability is disclosed to the instructor in the letters. The instructor acknowledges and approves the participant's accommodations through the online accommodation system. Once approved, the participant can then manage their accommodations through the online accommodation system. Participants are only required to meet one time with their DRC coordinator throughout their college career because their approved accommodations roll-over each semester. For example, once approved for $1.5 \times$ extended-time exams, the participant can select this accommodation for all of their classes in a new semester without meeting each semester with their DRC coordinator. Conversely, any changes to a participant's accommodations require communication with their DRC coordinator.

\section{Self-advocacy knowledge}

\section{Test's component: Knowledge of self}

Knowledge of self was defined as the awareness of individual strengths and weaknesses as a learner with a disability (Test et al., 2005). All our participants demonstrated knowledge of self by describing their strengths and weaknesses while in undergraduate STEM courses. For example, our participants detailed their strengths in math and science. Oakley stated, "I know that a lot of people, [especially] with...dyslexia, they sometimes struggle with math... But I happen to be better at math." Claudia also identified her strength in math explaining, "I always have been naturally better at math as opposed to English." One way our participants realized their strengths in math and science was through their previous success in STEM in high school. These realizations served as motivation to pursue a STEM major in college.

While our participants described their strengths as STEM majors, they also outlined their weaknesses. We found the weaknesses described by our participants to be consistent with the functional limitations associated with ADHD/SLD. Participants in our study mentioned issues with focus and attention, processing speed, reading, and organizing thoughts. In this section, we include the reported disability of each participant to inform the association between the knowledge of self and the type(s) of disability(ies) reported by the participant.

Several participants described issues with focus and attention that they experience while in an undergraduate STEM course. Challenges in focus and attention are a characteristic of ADHD (American Psychiatric Association, 2013). Our participants demonstrated knowledge

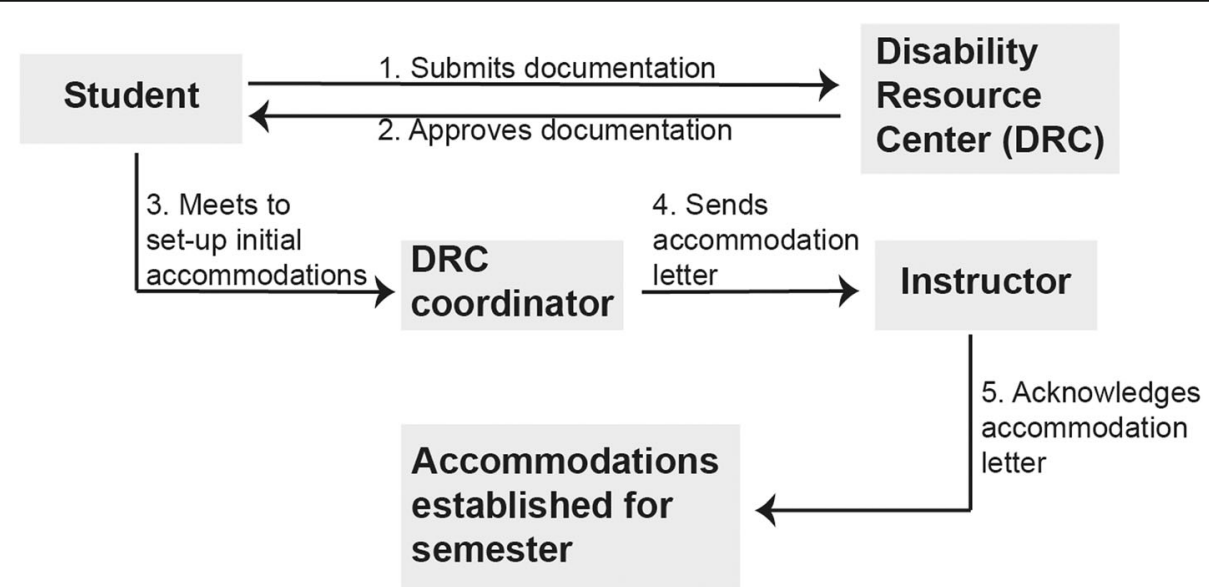

Fig. 3 Overview of the accommodation process our participants experienced to initially establish and use accommodations in undergraduate STEM courses. (1) Students with qualifying disabilities submit official documentation to the campus Disability Resource Center (DRC). (2) The DRC reviews and approves the documentation, and subsequently (3) the student can schedule an initial accommodation meeting with their assigned DRC coordinator. During this initial meeting, the student and their DRC coordinator agree on the accommodations the student will request in each of their courses, and (4) the DRC sends the instructors of these courses an official accommodation letter through the online accommodation system. (5) The instructor receives and acknowledges the accommodation letter, and the student's accommodations are established for the semester 
of self when they explained their experiences with focus and attention in the classroom. For example, Isabel shared the challenges she encounters with focus during a lecture.

When the professor is lecturing, I need for them to repeat what they just said because I may have caught part of it, I may have been distracted and working on a problem and I'm not able to work on a problem and listen to them at the same time.-Isabel, a student with ADHD

Isabel was aware that she may miss portions of a lecture because of challenges in maintaining focus and attention throughout the class period. Another participant, Opal detailed how her strong desire not to miss any of the lecture affects her as a learner with ADHD.

I'm trying to hold on to [the instructor's] words, while also holding on to what I'm writing down. It makes me feel like I left something behind. You can feel when you leave for the airport and you feel like you're leaving something behind, you get there and it's like your I.D. That's what it feels like to me... With my notes, I feel like I haven't gathered everything.-Opal, a student with ADHD

Opal described how taking notes during a lecture is stressful because she knows she is missing what the instructor says while she is writing. Her knowledge of self allowed her to articulate how this makes her feel in a way someone without ADHD can understand. While some participants described difficulty maintaining focus, other participants demonstrated knowledge of self by describing their experiences with hyperfocusing. Hyperfocusing involves prolonged attention to detail and is associated with ADHD (Hupfeld, Abagis, \& Shah, 2019). Some participants, such as Isabel, shared their experiences with hyperfocus, as it often demands extra time to complete exams and assignments. Isabel, explained, "Sometimes I get hyperfocused and detail-oriented. It takes me longer to do things." For Isabel, she especially notices that she hyperfocuses when she is working on math problems.

While several participants revealed their knowledge of self by discussing their experiences with focus and attention, other participants referred to challenges with processing speeds. For example, Cassie talked about what it is like to be a learner with slow processing speed and ADHD in undergraduate STEM courses.

I'm less likely to speak up and participate in group activities because...I do have a disability where I think slower. I'm less likely to be as engaged in group activities as other classmates... Part of it is,
I'm just sitting there processing what they're saying.

But they're going so much faster than me.-Cassie

Cassie explained that she is more likely to be quiet in an interactive STEM classroom because she is listening and processing information at a different speed than her peers. Other participants demonstrated knowledge of self by explaining how different processing speeds affect them while taking exams. For example, Megan talked about being a learner with dyslexia and ADHD, and how she uses extra time on exams to go through her thought process.

I need to organize my thoughts, look at problems, see everything I'm given, write it all down. I feel like I go through a lot more steps than most people would need to answer the question...-Megan

Megan described how she uses a process to ensure she does not miss relevant information while she reads the exam. Other participants with a specific learning disability in reading explained that their processes can involve highlighting information in certain colors to help draw attention to important words in exam questions. Such a process is vital for Megan's success on the exam and requires time to fully complete.

\section{Development of knowledge of self}

All of our participants demonstrated knowledge of self, and some participants also explained how they developed this knowledge. For example, some participants described developing knowledge of themselves as a learner with a disability from previous experiences.

I've had experiences where other people... constructively point [my weaknesses] out, and just myself internally just being like, "Hey, this is an area that I'm struggling in."-Mia

Mia shared that when she was first diagnosed with her disability in middle school, she worked with a reading tutor who was specially trained to help teach students with SLD in reading. Mia's tutor helped her identify weaknesses associated with her disability. The tutor's goal was to use this information to help Mia select methods to overcome those weaknesses so that she would be successful. Mia now uses self-reflection as a college student to help identify new weaknesses she was not aware of. This helps Mia to decide what action, if any, she needs to take to address the situation.

In contrast to Mia, many participants discussed that their official testing documentation informed their knowledge of self. For example, Oakley and Wyatt cited their official testing documentation to explain their 
strengths and weaknesses as a learner with a disability. Oakley stated:

The [doctors] explained...to me that the processing and verbal parts to my brain work at different speeds. So I can read a problem or if I was presented with a math problem or something, I could read it, understand it conceptually, even visualize it, but because the verbal part is not on the same par with the processing part, I don't process it correctly and I do the problem according to what I think it is, but that's not always [what the question asked].-Oakley

Oakley gleaned knowledge of self, in part, from her testing documentation. She used this knowledge of self to later communicate with her DRC coordinator and to defend her use of accommodations to peers who think accommodations are unfair. Similar to Oakley, Wyatt used his testing documentation to inform his knowledge of self. He explained that his short- and long-term memory, along with his processing speed, are at lower levels compared to other areas, such as reading comprehension, where he scored above average. For participants like Oakley and Wyatt, their testing documentation served as one way to develop knowledge of self.

\section{Test's component: Knowledge of rights}

Knowledge of rights in Test's conceptual framework of self-advocacy was defined as, "knowing one's rights as a citizen, as an individual with a disability, and as a student receiving services under federal law" (Test et al., 2005 , p. 50). In our analysis, we considered any instance a participant mentioned that a law ensured their access to accommodations in college to be evidence of knowledge of rights. We found that only two participants, Mia and Archie, discussed laws concerning their accommodation use in college spontaneously, without prompting, while 23 participants did not. When we asked Archie what it is like for him to talk to instructors about his disability, he said:

I'm not really afraid because I know I have legal protection...I'm assuming Section 504 of the Workers Compact of ' 73 would apply, considering that I got the same accommodation, the 504 stuff in high school._Archie

Archie demonstrated knowledge of rights because he directly names one law, Section 504 of the Rehabilitation Act of 1973, which mandates universities and colleges provide access to accommodations for students with disabilities. Archie's knowledge of rights appeared to originate from his experiences in high school when he received accommodations under a Section 504 plan.
When we asked our participants about self-advocacy, most did not refer to laws. Instead, we found that our participants would say they know their instructors have to provide accommodations. Kendra, who worries about what her instructors will think of her when she talks to them about having ADHD, said that she uses this knowledge to help her prepare to talk to them. She said,

It always makes me really nervous, but at some point, I'm like you know what, it's not up to them... They have to make that accommodation, regardless of their own personal opinions on the subject.-Kendra

Other participants, like River, cited university policy rather than any federal law. River noted, "It's university policy that professors have to accommodate people with disabilities." Both Kendra and River were aware that they have a right to accommodations, although they did not directly name federal law as the source of this right.

\section{Emergent component: Knowledge of accommodations and the process to obtain them}

Our definition of knowledge of accommodations and the process to obtain them consists of two-parts, awareness of (1) accommodations that are available to a student with ADHD and/or SLD and (2) how the accommodation process in college works, including knowledge of the student role, the DRC coordinator role, and the instructor role in the process. We found that many of our participants were still developing a knowledge of their accommodations, and this influenced their selfadvocacy. For example, Cassie explained that she has never requested a notetaking accommodation, although she qualifies to receive it, because she is still developing knowledge of this accommodation.

An accommodation that's an option is the notetaking [accommodation]. I just never had that in high school, so I think coming to college, I was like, I don't know what that is. I just opted out of that every semester for every class.-Cassie

At the end of the interview, the interviewer explained how the notetaking accommodation typically works for students. After hearing this explanation, Cassie stated that she would now seriously consider requesting the accommodation because she had a better understanding of how the accommodation would work for her. Other participants shared that they did not know they could request a certain type of accommodation in their undergraduate STEM courses until their DRC coordinator suggested it directly to them. One example of this was from Kendra, who reported that she did not know she could ask to audio-record lectures in her STEM courses 
instead of requesting a traditional notetaking accommodation. We found that many of our participants developed knowledge of accommodations through their DRC coordinator.

A majority of our participants demonstrated knowledge of the accommodation process when they explained to us how their accommodations worked from the start to the end of the semester. They described the roles and responsibilities of each party involved in the accommodation process in college, including the student, the DRC coordinator, and the STEM instructor. We considered this type of knowledge to be similar, yet distinct, to the sample subcomponents of leadership as defined by Test. Test specifically defined leadership as "awareness of the common needs and desires of others, working with others, group dynamics and responsibilities" (Test et al., 2005, p. 50). In Test's framework, leadership was not considered to be essential for selfadvocacy. We considered a baseline knowledge of accommodations and the process to obtain them likely an essential component of self-advocacy for our participants. We saw this type of knowledge to be an important component of self-advocacy that can be distinguished from leadership in our participants.

\section{Emergent component: Knowledge of STEM learning contexts}

We define knowledge of STEM learning contexts to be the awareness that accommodation needs are influenced by the learning environment experienced by students with ADHD/SLD in undergraduate STEM courses. This component of self-advocacy became salient during our analysis when many of our participants described their thought processes to determine what accommodations they wanted to request in a STEM course. Our participants explained that they consider the instructor expectations of students inherent to a particular learning environment when making accommodation decisions, and we term this thought process "task evaluation." We found evidence of ongoing task evaluation at a scale ranging from the entire STEM discipline to a single learning activity within a STEM course. We explain how our participants demonstrated their knowledge of STEM learning contexts within undergraduate STEM courses.

One participant, Wyatt, demonstrated knowledge of STEM learning contexts when he described how he decided to use his extended-time exam accommodation in one of his STEM courses. Within this particular STEM course, the lecture section of the course is $50 \mathrm{~min}$ in length and the laboratory section is at least $75 \mathrm{~min}$ in length. Wyatt shared that he first determined if the exams would be proctored in the lecture section of the course or in the lab section of the course before he signed up for extended-time exams at the DRC.
Other participants like Henry and Mia showed knowledge of STEM learning contexts when they described how they decide to use their available accommodations. For our participants, once they initially meet with their DRC coordinator, they have the freedom to select course-by-course what accommodation notification letters they will send to their STEM instructor through the online accommodation system. These are accommodation decisions participants make on their own, unless they request a follow-up meeting with their DRC coordinator. Henry described his thought process in making this type of accommodation decision for his STEM courses,

[I] figure out what the course is going to be. Is it going to be a lecture? Is it going to be group work? Is it going to be a lab? Is it actually a lab? Then see which of my accommodations actually apply...-Henry

At the time of this interview, Henry was early in his college career. Henry was still in the process of developing his knowledge of STEM learning contexts. He later explained that he would sometimes ask his STEM instructors if his accommodations would apply to STEM specific learning contexts, such as an organic chemistry laboratory section.

Our participants described other strategies besides talking to STEM instructors that they used to develop knowledge of STEM learning contexts. Isabel and Tyler shared that they will first attempt to complete a quiz or exam without their accommodations in an unfamiliar STEM learning context because they would prefer not to use their accommodations if they can earn a satisfactory grade without them. For participants, like Isabel and Tyler, they prioritized their own experience in unfamiliar STEM learning contexts. They did not seek out additional information about the learning context from their peers, teaching assistants, or instructors.

Several other participants shared with us that they did not know early in their STEM majors that they could request accommodations for assessments in lab sections, such as for a lab quiz or a lab practical. Kendra described her experience as a freshman in an undergraduate STEM course, where she ended up taking the lab practical without any accommodations, "I didn't even know at the time that I could have gotten accommodations for [the lab practical]." Kendra explained that taking her lab practical without accommodation in her freshman year was extremely stressful and she felt regretful when she later learned she could have requested them. Kendra's experience illustrates the importance of knowledge of STEM learning contexts. 


\section{Self-advocacy behaviors}

In our model of self-advocacy, we consider the components, communication, and leadership to be examples of self-advocacy behaviors. We describe how our participants engage in these behaviors to characterize how students practice self-advocacy in their undergraduate STEM courses. We also introduce and describe a novel behavior we term "filling gaps". We see communication as the heart of self-advocacy and that it is required for leadership and filling gaps.

\section{Test's component: Communication}

In Test's conceptual framework, communication is designated as an essential component of self-advocacy. Communication for the purpose of self-advocacy involves "negotiation, assertiveness, and problem-solving in a variety of situations" (Test et al., 2005, p. 50). We sought to uncover the variety of situations our participants engage in communication for the purpose of selfadvocacy. In this section, we describe situations involving communication with DRC coordinators and with STEM instructors. Our rationale for providing these examples of communication is to characterize the types of situations that warranted self-advocacy for our participants in the context of undergraduate STEM courses.

\section{Communication with DRC coordinators}

Once our participants registered with the DRC, they met with their assigned DRC coordinator to establish their accommodations. In the initial accommodation meeting, the participant and the coordinator agreed upon the accommodations the participant is eligible to request for the remainder of their college career at the university where data collection occurred (Fig. 3). For many participants, this initial meeting was the only time they communicated face-to-face with their DRC coordinator because they found their initial accommodations to be sufficient. However, several participants reported ongoing communication with their DRC coordinator to manage accommodation issues that developed after the initial accommodation meeting. We found that our participants communicated with their DRC coordinators about their extended-time exams, notetaking accommodations, and experiences with instructors.

Some participants communicated with their DRC coordinators to adjust the details of their extended-time exam accommodations. One example of participants adjusting their extended exams was given by Henry who communicated with his DRC coordinator to update the terms of his accommodations to better fit his needs as a student with an SLD in reading. He asked his DRC coordinator for an alternative format for his exam.
It was during the first exam. I didn't do as well as I normally did previously in high school. When I went back and looked over the exam, I realized it's some of the reading mistakes I make, and the format of the exam was on the computer. Normally in high school, since everything was on paper, I could go back and highlight and underline and help myself focus. I wouldn't make as many reading mistakes. So then when I realized that was the problem, I went back to my DRC coordinator and I talked to her about it and then we got printed written exams.-Henry

Henry recognized that he is likely to perform better on exams if he reads the exam in a print format instead of on a computer screen. Henry successfully communicated with his coordinator to make this change to his exam accommodations.

Our participants also described self-advocating by communicating with their DRC coordinators, or the DRC office, when exam scheduling issues arise. The DRC at the university where data collection took place requires students taking exams at the DRC to schedule their exam 7 days in advance. Many of our participants shared instances where they missed the 7-day deadline. Some participants in this situation did not attempt to communicate with the DRC and decided to take the exam in class, without their accommodation(s). We found that a subset of our participants demonstrated self-advocacy in this situation by communicating with the DRC to see if it was still possible for them to use their accommodations and take the exam at the DRC.

Besides extended-time exams, many of our participants qualified for a notetaking accommodation. At the institution where data collection occurred, the notetaking accommodation typically entailed the STEM instructor identifying a student in the class who agreed to upload a copy of their own notes to the DRC's online accommodation portal. The identity of the notetaker was usually unknown by the student requesting the accommodation. Once the notes were uploaded, the student using the accommodation could access the notes, and the notetaker was compensated $\$ 100$ for their service. Our participants frequently reported to us that they have received low-quality notes from their DRC-paid notetaker. However, only one participant in our study, discussed issues about her notetaking accommodation with her DRC coordinator when she did not receive any notes.

The one time I did [use a notetaker] I had issues. First of all, my first notetaker never sent me notes, so I just notified the DRC and they got me a new notetaker. Then that notetaker was very subpar... 
but I was doing well in the class so I never tried to find another one.-Megan

Megan only described communicating with the DRC about notetaking when she failed to receive any notes from her assigned notetaker. She did not communicate with the DRC to inform them that the notes she eventually received were of poor quality. Because several other participants had a similar experience with their notetaking accommodation, we asked participants why they chose not to communicate to their DRC coordinator when they received low-quality notes from their notetaker. Our participants expressed concern that if they reported the issue, the notetaker would no longer be paid $\$ 100$ from the DRC. Issues with notetaking accommodations were prevalent in our data. However, situations where our participants communicated with their DRC coordinators about issues with notes were rare.

\section{Communication with STEM instructors}

In the following subsection, we detail how our participants described communication with their STEM instructors. We included these data because participants are not required to directly communicate with their STEM instructors about their disability or accommodations at the university where data collection occurred. In addition, all our participants use accommodations for invisible disabilities, so their instructors would not necessarily recognize them as a student using accommodations in their classrooms. We were interested in the experiences and perspectives of our participants: do they communicate directly with their STEM instructors about their disability and accommodations use? We also wanted to know what factors they considered in making the decision to talk directly to their STEM instructors about their disability and accommodation use.

Some participants found value in communicating with their STEM instructors about their accommodations. Isabel explained that she communicates with all her STEM instructors about her accommodations so she can gauge how familiar the instructor is with their role in the accommodation process.

Some [STEM instructors] have a harder time accommodating than others...So, it's good to have that face-to-face contact [with STEM instructors] to communicate or get an understanding if they've had students who use accommodations before, if they know the process...-Isabel

Isabel explained that the instructor's familiarity with the accommodation process in college will determine how much follow-up communication she has with the instructor. This helps Isabel determine how much self- advocacy she will likely need to enact in a particular course, to ensure she receives her accommodations. A few of our participants, such as Mia and Eli, reported that they always discuss their accommodations and disclose what disability or disabilities they receive accommodations for with their STEM instructors. Mia tells all her STEM instructors that she has an SLD in reading because she sees it as a means to make a personal connection and to inform the instructor so they can work together in the accommodation process if issues arise.

I always discuss [my disability] with my professors... I feel like that's more courteous and it's also putting a face to the name and making it easier ultimately on both parties to recognize where we need to work together... Often, I'm just like, "I have dyslexia. It is what it is. I have these accommodations and if you have questions, then let me know."-Mia

Mia prefers to talk openly about her accommodations and disability with her STEM instructors. She operates under the assumption that the instructor wants to support her learning and accommodation use but thinks that the instructor may need more information than the official accommodation letter provides to do this successfully. For Mia, this conversation is an essential piece of her self-advocacy with an instructor.

Our participants also described situations when they communicated with their STEM instructors about their accommodations. Typically, these situations involved determining the logistics of a specific accommodation, such as extended-time exams, or finding a notetaker. Many participants, especially those in engineering majors, described communicating with their instructors to determine if they would take an extended-time exam at the DRC, or if the STEM instructor would proctor the extended-time exam in-house. Several of our participants shared that many of their engineering courses do not use traditional exams but, instead, require students to work in groups on projects that are submitted as an exam grade. Besides determining exam logistics, our participants also communicated with their STEM instructors to arrange accommodations for in-class quizzes and online exams. Claudia described how she recently communicated with a STEM instructor regarding pop quizzes,

I went up to him and I said, "I'm struggling to finish these pop quizzes, this is stressful. I'm set up with extra time for my tests. Is it possible for there to be any sort of way to get extra time on these quizzes?" At first he said no, and I was like, "I'm not finishing these, I'm stressed out," and he said, "Okay, the best I can do is putting your paper down first and then 
picking yours up last," and I said, "I will do it, sounds good."-Claudia

Claudia later shared that this arrangement afforded her about 45 additional seconds on the quiz. Claudia felt satisfied with the solution. She successfully communicated for the purpose of self-advocacy by negotiating with her STEM instructor. Many participants described situations where communication with their STEM instructor was needed for the purpose of self-advocacy.

\section{Test's component: Leadership}

In Test's conceptual framework of self-advocacy, leadership was broadly defined as, "an awareness of the common needs and desires of others, working with others, group dynamics and responsibilities" (Test et al., 2005, p. 50). Examples of leadership could involve "working with others to speak up for their collective wants and needs through organization, community gatherings, and political forums" (Test et al., 2005, p. 50). Leadership was not considered to be essential for self-advocacy in Test's conceptual framework. We considered participants to show evidence of leadership when they discussed taking actions on the behalf of others, relating to issues of disability or accommodations. We only found a few examples of leadership, but the leadership described by our participants could be categorized into two types: taking action for others with diagnosed disabilities to overcome stigma and advocating for peers without formally diagnosed disabilities to be tested to receive academic accommodations. One example of leadership was from Oakley who showed leadership by engaging in a research project to find genetic markers for ADHD.

I wanted to find a genetic marker to correlate with people who had been diagnosed with ADHD and I actually found one in a very small population size. But the whole reason I did that was because I wanted to reduce the stigma around ADHD.-Oakley

Oakley demonstrated leadership when she expressed that her motivation to conduct research was to reduce the stigma of ADHD for other people with ADHD. She demonstrated awareness that other people with ADHD wish that the condition was more broadly accepted as a legitimate disability, validating the need for academic accommodations.

\section{Emergent component: Filling gaps}

We found that many of our participants described a novel collection of behaviors, associated with selfadvocacy, that we call filling gaps. We define filling gaps as participant actions taken to overcome limitations in formal accommodations or instructional supports to ensure success as a learner with ADHD/SLD in undergraduate STEM courses. We see filling gaps as involving communication that extends beyond the bounds of the established accommodation and support systems that existed at the university where data collection occurred.

Many of our participants demonstrated that they recognized how, at times, their formal accommodations or instructional supports within a certain STEM course were not sufficient. For example, many of our participants reported receiving low-quality notes from their DRC-paid notetaker. While only one of our participants ever communicated with the DRC to make them aware of this issue, several of our participants describe filling the gap in this formal accommodation by establishing their own system to receive sufficient notes in a timely manner. One example of filling gaps comes from Mia who described how she set up a Google doc with her peers in her upper-division biology class to ensure she has access to a quality set of notes because if she missed information in class, one of her peers was likely to write it down, and viceversa. This ensured that everyone in her peer group could access quality notes after class. Heath set up a similar system to take notes. He explained how developing his own note system is a form of self-advocacy,

I do my own form of accommodating by having another support system that is not the DRC that I can fall back on.-Heath

Another prevalent example of filling gaps in our data comes from participants who do not feel they can ask their STEM instructors questions about class material either after class or in office hours. Several of our participants expressed that they do not perceive their instructors to be approachable, so instead of going to office hours, they will seek out tutoring from a peer, or a third-party tutoring service. For example, Ryan shared that he has asked a peer in his upper-division STEM course to tutor him because there are no qualified tutors available at the university's office of academic enhancement and because he does not perceive his instructors to be approachable.

Our participants described filling gaps as a way they practice self-advocacy in their undergraduate STEM courses. We found that many participants may or may not disclose their disability status when they fill gaps. For example, they could ask their peers to take notes with them while their peers may or may not know they qualify for academic accommodations. We also asked our participants if they told their tutors about having a disability, and they said it never came up. 


\section{Emergent components: Beliefs influencing participant self-advocacy}

In our analysis, we found that beliefs held by our participants influenced self-advocacy knowledge and selfadvocacy behaviors. Agency and view of disability are the beliefs we found our participants to discuss when they described their self-advocacy. Each belief is detailed in the following sections.

\section{Agency}

We found that participants who strongly articulated a belief that they are the person responsible for their own accommodations and success in college tended to describe more components of self-advocacy. This belief is a form of agency, which is the belief that you are responsible for your own learning (Baxter Magolda, 2000). For example, Opal demonstrated agency when she explained how she "defends [herself] in a way" in a situation where her peers stated that the only reason Opal earned a better grade than them on an exam was because Opal qualifies for an extra time accommodation. Opal responded,

I took it [into my] own hands, because I was struggling. I went and [asked] for help and figured that out for myself, so what's your problem with it? If you want extra time, go get tested, and go figure it out for yourself.

Other participants like Kendra and Henry also explained how they perceive themselves to be the person responsible for their own success and this influences how they engage in self-advocacy. Kendra described her perspective,

The best thing...for me has been learning that if I need something, I have to learn how to do it myself. I know that if I don't go up to them and tell them, then I'm not going to get what I need.-Kendra

Kendra described how she knows she has to be the person to talk to her DRC coordinator or her STEM instructors if she needs an accommodation. Henry expounded on his perception of the student role in the accommodation process by stating, "If a problem arises, I go confront it, and I say I have this accommodation I would like to apply to this situation." Henry demonstrated agency by describing that he takes responsibility for his own accommodations and does not solely rely on his DRC coordinator to mediate situations with his STEM instructors. At times, for Henry, this was challenging because one of his STEM instructors stated they would prefer if Henry first contacted his DRC coordinator before speaking to them. Statements from Opal,
Kendra, and Henry clearly illustrated that they see themselves as responsible for their own accommodations, and this idea was linked to their self-advocacy. These strong agentic statements were in contrast to some of our other participants, like Dana, who stated that she wished her DRC coordinator "would just send [her accommodation letters] to her instructors" without Dana having to initiate the request because Dana was prone to "procrastinating and forgetting." Dana did not appear to fully embrace her own role in the accommodation process and did not practice self-advocacy to the same extent as other participants.

\section{View of disability}

View of disability strongly influenced self-advocacy. Our participants described their own view of disability, and their perceptions of how STEM instructors and peers view disability and accommodation use in the context of undergraduate STEM courses. Our participants reported a continuum of views regarding their own disability which ranged from negative to positive. Participants who tended to express a positive view of their disability also tended to describe more components of self-advocacy. This was exemplified by Mia, who showed multiple components of self-advocacy and who stated that she "is proud" of having dyslexia. Other participants like Opal explained that she does not see her disability "as a burden, or something that makes me lesser...it is just part of my chemical makeup."

Another participant, Henry, shared that his knowledge of self informs his personal view of disability. He stated that he is aware that his SLD "changes the speed at which I intake and export information" but he does not "feel ashamed that I need [accommodations] because sometimes I think I'm smarter than people without accommodations because I had to work so hard to get to the same level of speed." Henry explained that he thinks this extra work related to his SLD causes him to have a stronger knowledge base than some of his peers.

Participants who tended to see their disability in a positive manner described using accommodations, like Oakley, when she said, accommodations "level the playing field" between her and her peers without a diagnosed disability. Participants who felt their disability was shameful or embarrassing tended to describe feeling conflicted about using accommodations because they worried about what other people, like their STEM instructors and peers, would think about them if they found out. Aaron who tended to describe a negative view of his disability also explained that he worries about what his STEM instructors think of students who use accommodations. He explained that back when he would still sometimes use accommodations, he would meet with each STEM instructor and ask, "Do you think 
this makes me look like a lesser student?" Aaron would then determine how genuine his instructor's response was to this question. Aaron explained how one math instructor reassured him that it was okay for Aaron to use accommodations in his class,

... he kind of said like with [my upper-division math course] time isn't a concern, because you can solve a problem for years, so I shouldn't be worried about it. So, he gave me... a concrete example of like why I shouldn't be worried.-Aaron

This interaction with his STEM instructor made Aaron feel comfortable to use accommodations in this STEM course. Conversely, Aaron shared another example of when his STEM instructor did not respond in a timely manner to his accommodation request. Aaron did not want to confront the instructor to ask why so he "cancelled" the request and decided to "take a new class."

Overall, many participants expressed that they perceive self-advocacy to be more challenging in STEM courses compared to other disciplines because they perceive their STEM instructors to think negatively about students with disabilities and accommodation use in their courses. Mia expressed her perception of STEM instructors' beliefs about students who use accommodations:

A lot of times, professors are like, "STEM courses are for the smartest kids and you don't need accommodations if you're smart..." Versus like a nonSTEM course, they're just like, "Oh yeah, I have worked with plenty of people who have accommodations. It's just another day."-Mia

We found one counterexample in Kendra who stated she felt that her STEM instructors would be more understanding of her disability, ADHD, because they were scientists and tended to be more "empirical." However, several of our participants perceived their STEM instructors to hold negative views of students who use accommodations in their courses, and consequently, selfadvocacy in STEM could be more challenging to enact.

\section{Discussion}

We identified components of self-advocacy that are evident among 25 STEM majors through semi-structured interviews and qualitative analysis. We propose a model of self-advocacy for students with ADHD/SLD in undergraduate STEM courses based on our participants' experiences (Fig. 2). From our model of self-advocacy, we propose hypotheses regarding self-advocacy for students with ADHD/SLD in undergraduate STEM courses. Further testing of these hypotheses will determine if they apply to students in other contexts. In the following sections, we explain our hypotheses and situate them within existing literature. We also suggest implications for research and teaching if these hypotheses are supported by future research.

\section{Hypothesis 1: Self-advocacy for students with ADHD/SLD in the context of undergraduate STEM courses requires novel forms of self-advocacy knowledge}

We propose that additional forms of knowledge besides knowledge of self and knowledge of rights are involved in self-advocacy for students with ADHD/SLD in undergraduate STEM courses, namely, knowledge of accommodations and the process to obtain them, as well as knowledge of STEM learning contexts. We found knowledge of accommodations and the process to obtain them to be a stand-alone component of self-advocacy because this type of knowledge was distinct from knowledge of rights. Few participants directly named federal legislation that guides the accommodation process in college. However, many participants explained their knowledge of the accommodation process at the university where data collection occurred. We found several examples of how our participants developed knowledge of accommodations and the impact this knowledge or lack of this knowledge had on their self-advocacy. For example, Cassie told us that the main reason she decides not to use her notetaking accommodation in undergraduate STEM courses is because she did not use a notetaking accommodation in high school and she does not know how it works. In another study of college students with learning disabilities, students who had inaccurate information about accommodations and the process to obtain them tended to not disclose their disability status to the university and, as such, did not use accommodations (Cole \& Cawthon, 2015). Separating knowledge of rights from knowledge of accommodations and the process to obtain is logical (Vaccaro et al, 2015). Federal laws mandating access to accommodations for students with disabilities are the same across the country; however, the process by which students access these accommodations differs by institution. Thus, knowledge of accommodations and the process to obtain them at a student's home university is likely critical for practicing self-advocacy.

We propose knowledge of STEM learning contexts is a novel form of self-advocacy knowledge for students with ADHD/SLD in undergraduate STEM courses. Undergraduate STEM courses are known to possess unique barriers for students with disabilities. For example, STEM courses often encompass components besides traditional lecture-style classrooms including labs, fieldwork, small-group work, and design studios, which we refer to as "a STEM learning context" (Moon et al., 
2012). Our data show that many of our participants consider the contexts of their STEM courses when making accommodations decisions and actively seek to develop this type of knowledge. This is evident in Henry when he describes evaluating the tasks in a given STEM course to determine if he will request formal accommodation for the course. For example, he met with his organic chemistry instructor to ask if his accommodations will apply to his organic chemistry lab quizzes and lab practical. These data suggest STEM instructors can play a role in helping students to develop knowledge of STEM learning contexts.

If hypothesis 1 is supported by future research, interventions to promote development of knowledge of accommodations and knowledge of STEM learning contexts would be appropriate. It would also call on STEM instructors to consider adopting practices in their courses to support student development of knowledge of STEM learning contexts. Instructors could consciously incorporate explanation of the STEM learning contexts students will experience in their course using multiple means of representation, not only in an accessible course syllabus, but also through other avenues such as instructor talk, which is language an instructor uses to create the learning environment (Seidel, Reggi, Schinske, Burrus, \& Tanner, 2015).

Hypothesis 2: Beliefs, such as agency and perceived view of disability, influence self-advocacy for students with ADHD/SLD in undergraduate STEM courses

We found that self-advocacy for our participants could be influenced by agency. In the context of our study, agency was defined as a sense of responsibility for your own learning as a student with ADHD/SLD. We found participants who demonstrated agency tended to describe more forms of self-advocacy. For example, Opal, Kendra, and Henry demonstrated agency when they explain a personal responsibility to ensure they can access the accommodations they need in an undergraduate STEM course. Our finding that self-advocacy is influenced by agency is consistent with what is known about self-advocacy. Self-advocacy is considered to be a component of self-determination (Test et al., 2005; Wehmeyer et al., 2003). Self-determination is a construct rooted in broader theories of human agency, and thus, self-advocacy is linked to agency (Walker et al., 2011).

Our data show that the self-advocacy of our participants was also influenced by view of disability. View of disability for our participants included the view of their own disability, and their perceptions of how other people, including STEM instructors and peers, view disability and accommodation use in undergraduate STEM courses. We found that participants who viewed their own disability in a positive manner tended to describe more components of self-advocacy. For example, Mia told us she is proud of her SLD in reading and she demonstrated evidence for nearly all a priori and emergent forms of self-advocacy. Similarly, a positive view of disability was found in another study of college students with learning disabilities to be a factor related to deeper disclosure of disability to the university and college instructors (Cole \& Cawthon, 2015).

In our study, participants who described substantial concerns about how others in their STEM courses viewed disability appeared to struggle to practice selfadvocacy. This was evident in Aaron who would cancel his accommodation requests when a STEM instructor did not respond in a short period of time because he interpreted this to mean that his STEM instructor viewed disability and accommodation use negatively. It is important to underscore that this was Aaron's perception, which may or may not reflect the actual view of disability held by the STEM instructor. Our data show that participants' perceptions of how their peers and STEM instructors view disability and accommodation use impacted their self-advocacy.

We consider view of disability to be related to campus climate towards students with disabilities. Campus climate can be defined as "a measure of people's attitudes about, perceptions of, and experiences within a specified environment" (Ryder \& Mitchell, 2013, p. 34). It has been suggested that students with disabilities often perceive campus climates to be less welcoming than students without disabilities (Harbour \& Greenberg, 2017). Student perceptions of college faculty, in general, are that college faculty are willing to accommodate students with disabilities, but faculty are perceived to be skeptical about the legitimacy of ADHD as a disability necessitating academic accommodations (Stamp, Banerjee, \& Brown, 2014; Yssel, Pak, \& Beilke, 2016). Few studies examine the attitudes of STEM faculty and peers without disabilities towards students with disabilities in undergraduate STEM courses. In a small-scale study of five STEM faculty, participants indicated they are willing to accommodate students with disabilities in their courses (Love et al., 2014). Beyond this study, there is a dearth of literature regarding attitudes of STEM faculty towards students with invisible disabilities, such as ADHD. In our study, many participants perceived STEM faculty as less receptive to their accommodation needs compared to faculty in other disciplines.

The notion that the culture of STEM may be less welcoming to students with learning disabilities compared to other disciplines is supported by a few previous studies. For example, researchers investigating students with learning disabilities in undergraduate STEM courses reported that they perceived their own research to be marginalized because STEM faculty and staff did not appear 
to consider students with learning disabilities to be capable of conducting STEM work (Thurston et al., 2017). Moreover, the use of accessible teaching approaches known to reduce barriers for students with disabilities in K-12 STEM education, called universal design for learning, is not widely adopted in undergraduate STEM courses (Schreffler et al., 2019). The fact that universal design for learning is known to be helpful for students with disabilities, yet is not frequently used in undergraduate STEM courses suggests the climate is not as welcoming as it could be to all students with disabilities.

Future studies examining how students with ADHD/ SLD, as well as other disabilities, perceive undergraduate STEM courses and departments are needed. Our data suggest that students with ADHD/SLD form perceptions of how their STEM instructors and peers view disability and the use of accommodations in undergraduate STEM courses, sometimes without even any verbal exchanges at all. These perceptions of how disability is viewed have the potential to greatly influence the decision to use accommodations in a STEM course. We stress that these perceptions may or may not reflect the actual view of disability held by STEM instructors and peers, yet regardless these perceptions are likely at play when students decide whether or not to engage in self-advocacy. It is thus imperative that we understand how students with ADHD/SLD perceive the climate of their STEM courses so that we can take steps to make undergraduate STEM courses more welcoming and inclusive.

Hypothesis 3: Students with ADHD/SLD in undergraduate STEM courses engage in behaviors we call "filling gaps" to be successful in their undergraduate STEM courses

Our participants engaged in a novel set of behaviors we refer to as "filling gaps." Filling gaps involved our participants seeking out other people or resources to help them succeed in their undergraduate STEM courses. These behaviors involved going beyond officially sanctioned DRC accommodations or formal instructional supports. Examples of filling gaps came from Mia and Heath who described how they established their own notetaking systems with peers in a STEM course and from other participants, like Ryan, who discussed seeking out peer tutors. For some of our participants, filling gaps was a way they could access the supports they needed without having to necessarily disclose their disability status. Two studies examining the experiences of education majors with learning disabilities hint at the importance of informal supports during college for their participants (Couzens et al., 2015; Timmerman \& Mulvihill, 2015). For example, one study reported that two of their participants, one participant who is a student with multiple disabilities, including ADHD and SLD, and another who is blind, described situations reminiscent of filling gaps in our study (Timmerman \& Mulvihill, 2015). Their participants noted how friends or peers would occasionally help them by volunteering to read textbooks aloud or by providing copies of class lecture notes. However, both these participants noted that the willingness of their classmates to help may be because they are all special education majors and that this environment was likely to be more accepting of students who use accommodations, compared to other majors (Timmerman \& Mulvihill, 2015).

If hypothesis 3 is supported by future research, it would connect self-advocacy to social capital. Social capital involves the resources that are afforded to and utilized by an individual through their connections to other people within a social network (Lin, 2001). A previous study of STEM majors with disabilities found selfreported gains in self-advocacy skills after participation in a learning community that built social capital (Whitney, Langley-Turnbaugh, Lovewell, \& Moeller, 2012). If filling gaps and self-advocacy are indeed connected, universities and STEM departments committed to the success of STEM majors with ADHD/ SLD should pursue programming interventions that are likely to promote development of social capital. Interventions such as the formation of peer learning communities (e.g., Whitney et al., 2012) and opportunities for mentorship from graduate students, coupled with disability-related instruction from experts (e.g., Kreider et al., 2018) are examples of interventions that may help students access social capital to help fill gaps to enhance self-advocacy.

\section{Considerations for transferability of our findings}

Data were collected at one institution, which may limit the transferability of the findings to other settings. However, by limiting our data collection to one institution we were able to pursue clarifications for incongruities we encountered in our data (Stanton, Dye, \& Johnson, 2019). For example, our participants referred to the DRC and the online accommodation system using many different names and we were able to clarify these terms. Our sample represents a convenience sample. All our participants were registered with the DRC. It is possible that our sample is missing some self-advocacy experiences of students with ADHD/SLD who are navigating college without formal accommodations. Yet the purpose of our study is to characterize the self-advocacy experiences of students with ADHD/SLD in undergraduate STEM courses. We reasoned that students registered with the DRC practice self-advocacy and would be willing to discuss their experiences with us. Our sample is likely enriched for self-advocacy. 


\section{Conclusion}

In conclusion, the 25 STEM majors with ADHD/SLD in our study described their self-advocacy experiences in the context of undergraduate STEM courses. Based on our analysis of participants' experiences, we provide the first empirically derived model of self-advocacy for students with ADHD/SLD in undergraduate STEM courses. In our model, we operationalized components of Test's original conceptual framework of self-advocacy by determining how our participants demonstrated knowledge of self, knowledge of rights, communication, and leadership in undergraduate STEM courses. We proposed additional components of self-advocacy knowledge and selfadvocacy behaviors and identified beliefs which influenced self-advocacy in our participants. Together, these original and emergent components comprise an updated model of self-advocacy based on the experiences of our participants. Future testing of this model will permit development of a theoretical framework of self-advocacy for students with ADHD/SLD in undergraduate STEM courses. Such a theoretical framework can be used to develop valid and reliable measures of self-advocacy that, in turn, can be used to determine the effectiveness of interventions designed to promote and enhance selfadvocacy for students. By promoting self-advocacy within students, we can help increase the retention rates of students with ADHD/SLD in undergraduate STEM courses and majors, which will lead to a more diverse and competitive STEM workforce.

\section{Supplementary information}

Supplementary information accompanies this paper at https://doi.org/10. 1186/s40594-020-00233-4.

Additional file 1: Supplemental Table 1. Components of selfadvocacy codebook.

Additional file 2. Supplementary Text: Interview protocol.

\section{Abbreviations}

ADHD: Attention-deficit/hyperactivity disorder; DRC: Disability Resource Center; SLD: Specific learning disorder or specific learning disability; STEM: Science, technology, engineering, and mathematics

\begin{abstract}
Acknowledgements
We are grateful for the opportunity to learn from our participants, and we thank members of the Disability Resource Center (DRC) at the University of Georgia speakers' bureau for assistance in initial interview protocol development. We are especially appreciative for the feedback and support of our partners at the DRC, including Erin Benson, Sam Adair, and Patricia Roth Marshall. We thank members of the Biology Education Research Group (BERG) at the University of Georgia for critical comments and feedback throughout the life of the project and on an early version of the manuscript.
\end{abstract}

\section{Authors' contributions}

MAP and JDS designed the study. MAP collected data. MAP, EMR, MH, and JDS analyzed data. MAP, EMR, and JDS developed the model. MAP and JDS collaborated on manuscript writing. All authors read and approved the final manuscript.

\section{Funding}

This material is based upon work supported by the National Science Foundation Graduate Research Fellowship Program under grant number 1842396 (in support of MAP) and by the National Science Foundation under grant number 1659423 (in support of MH). Any opinions, findings, and conclusions or recommendations expressed in this material are those of the author(s) and do not necessarily reflect the views of the National Science Foundation. This research was supported in part by funds from the Division of Student Affairs at the University of Georgia (to JDS and MAP).

\section{Availability of data and materials}

Interview questions and the codebook used in this study are available in Supplemental Materials. Data generated and analyzed may be available from the corresponding author on reasonable request.

\section{Competing interests}

The authors declare that they have no competing interests.

\section{Author details}

${ }^{1}$ Department of Plant Biology, University of Georgia, Athens, GA 30602, USA. ${ }^{2}$ Department of Cellular Biology, University of Georgia, Athens, GA 30602, USA. ${ }^{3}$ Department of Psychology, Smith College, Northampton, MA 01063, USA.

Received: 28 December 2019 Accepted: 17 June 2020

Published online: 06 July 2020

\section{References}

American Psychiatric Association. (2013). Diagnostic and statistical manual for mental disorders (5th ed.). Washington, DC: Author.

Americans with Disabilities Act of 1990, Pub. L. No. 101-336, § 2, 104 Stat. 328 (1990).

Baxter Magolda, M. B. (2000). Interpersonal maturity: Integrating agency and communion. Journal of College Student Development, 41(2), 141-156.

Berghs, M., Atkin, K., Graham, H., Hatton, C., \& Thomas, C. (2016). Implications for public health research of models and theories of disability: A scoping study and evidence synthesis. Public Health Research, 4(8), 1-166. https://doi.org/10. 3310/phr04080.

Budd, J., Fichten, C. S., Jorgensen, M., Havel, A., \& Flanagan, T. (2016). Postsecondary students with specific learning disabilities and with attention deficit hyperactivity disorder should not be considered as a unified group for research or practice. Journal of Education and Training Studies, 4(4), 206-216.

Carabajal, I. G., Marshall, A. M., \& Atchison, C. L. (2017). A synthesis of instructional strategies in geoscience education literature that address barriers to inclusion for students with disabilities. Journal of Geoscience Education, 65(4), 531-541.

CAST. (2020). Universal Design for Learning Guidelines version 2.2. http:// udlguidelines.cast.org.

Charmaz, K. (2006). Constructing grounded theory: A practical guide through qualitative analysis. Sage.

Cole, E. V., \& Cawthon, S. W. (2015). Self-disclosure decisions of university students with learning disabilities. Journal of Postsecondary Education and Disability, 28(2), 163-179.

Costello, C. A., \& Stone, S. L. M. (2012). Positive psychology and self-efficacy: Potential benefits for college students with attention deficit hyperactivity disorder and learning disabilities. Journal of Postsecondary Education and Disability, 25(2), 119-129.

Couzens, D., Poed, S., Kataoka, M., Brandon, A., Hartley, J., \& Keen, D. (2015). Support for students with hidden disabilities in universities: A case study. International Journal of Disability, Development and Education, 62(1), 24-41. https://doi.org/10.1080/1034912X.2014.984592.

Curry, L. A., Nembhard, I. M., \& Bradley, E. H. (2009). Qualitative and mixed methods provide unique contributions to outcomes research. Circulation, 119(10), 1442-1452. https://doi.org/10.1161/circulationaha.107.742775.

Daly-Cano, M., Vaccaro, A., \& Newman, B. (2015). College student narratives about learning and using self-advocacy skills. Journal of Postsecondary Education and Disability, 28(2), 213-227.

Dunn, C., Rabren, K. S., Taylor, S. L., \& Dotson, C. K. (2012). Assisting students with high-incidence disabilities to pursue careers in science, technology, engineering, and mathematics. Intervention in School and Clinic, 48(1), 47-54. https://doi.org/10.1177/1053451212443151. 
DuPaul, G. J., Gormley, M. J., \& Laracy, S. D. (2013). Comorbidity of LD and ADHD: Implications of DSM-5 for assessment and treatment. Journal of Learning Disabilities, 46(1), 43-51.

Eckes, S. E., \& Ochoa, T. A. (2005). Students with disabilities: Transitioning from high school to higher education. American Secondary Education, 33(3), 6-20.

Eisner, E. W. (1991). The enlightened eye: Qualitative inquiry and the enhancement of educational practice. Merrill.

Fleming, A. R., Plotner, A. J., \& Oertle, K. M. (2017). College students with disabilities: The relationship between student characteristics, the academic environment, and performance. Journal of Postsecondary Education and Disability, 30(3), 209-221.

Foster, A., Urquhart, C., \& Turner, J. (2008). Validating coding for a theoretical model of information behaviour. Information Research, 13(4), $358 \mathrm{http}: / /$ InformationR.net/ir/13-4/paper358.html.

Fram, S. M. (2013). The constant comparative analysis method outside of grounded theory. The Qualitative Report, 18(1), 1-25 https://nsuworks.nova. edu/tar/vol18/iss $1 / 1$.

Gelbar, N., Madaus, J. W., Dukes, L., Faggella-Luby, M., Volk, D., \& Monahan, J. (2019). Self-determination and college students with disabilities: Research trends and construct measurement. Journal of Student Affairs Research and Practice, 163-181 https://doi.org/10.1080/19496591.2019.1631835.

Golafshani, N. (2003). Understanding reliability and validity in qualitative research. The Qualitative Report, 8(4), 597-607 https://nsuworks.nova.edu/tar/vol8/ iss $4 / 6$

Hadley, W. M. (2007). The necessity of academic accommodations for first-year college students with learning disabilities. Journal of College Admission, 195, 9-13.

Haegele, J. A., \& Hodge, S. (2016). Disability discourse: Overview and critiques of the medical and social models. Quest, 68(2), 193-206. https://doi.org/10.1080/ 00336297.2016 .1143849

Harbour, W. S., \& Greenberg, D. (2017). Campus climate and students with disabilities. NCCSD Research Brief, 1(2) http://hdl.handle.net/10919/86931.

Holzberg, D. G., Test, D. W., \& Rusher, D. E. (2019). Self-advocacy instruction to teach high school seniors with mild disabilities to access accommodations in college. Remedial and Special Education, 40(3), 166-176.

Hong, B. S. (2015). Qualitative analysis of the barriers college students with disabilities experience in higher education. Journal of College Student Development, 56(3), 209-226.

Hupfeld, K. E., Abagis, T. R., \& Shah, P. (2019). Living "in the zone": hyperfocus in adult ADHD. ADHD Attention Deficit and Hyperactivity Disorders, 11(2), 191208. https://doi.org/10.1007/s12402-018-0272-y.

Isaacson, M. D., \& Michaels, M. (2015). Ambiguity in speaking chemistry and other STEM content: Educational implications. Journal of Science Education for Students with Disabilities, 18(1), 1-9.

Izzo, M., \& Lamb, M. (2002). Self-determination and career development: Skills for successful transitions to postsecondary education and employment. [White paper]. Post-School Outcomes Network of the National Center on Secondary Education and Transition (NCSET) at the University of Hawaii at Manoa. http://www.ncset.hawaii.edu/Publications

Janiga, S. J., \& Costenbader, V. (2002). The transition from high school to postsecondary education for students with learning disabilities: A survey of college service coordinators. Journal of Learning Disabilities, 35(5), 463-470.

Kinney, A. R., \& Eakman, A. M. (2017). Measuring self-advocacy skills among student veterans with disabilities: Implications for success in postsecondary education. Journal of Postsecondary Education and Disability, 30(4), 343-358.

Krefting, L. (1991). Rigor in qualitative research: The assessment of trustworthiness. American Journal of Occupational Therapy, 45(3), 214-222.

Kreider, C. M., Medina, S., Lan, M.-F., Wu, C.-Y., Percival, S. S., Byrd, C. E., Delislie, A., Schoenfelder, D., \& Mann, W. C. (2018). Beyond academics: A model for simultaneously advancing campus-based supports for learning disabilities, STEM students' skills for self-regulation, and mentors' knowledge for coregulating and guiding. Frontiers in Psychology, 9. https://doi.org/10.3389/ fpsyg.2018.01466

Lee, A. (2011). A comparison of postsecondary science, technology, engineering, and mathematics (STEM) enrollment for students with and without disabilities. Career Development for Exceptional Individuals, 34(2), 72-82 https://doi.org/10.1177/0885728810386591.

Lee, A. (2014). Students with disabilities choosing science technology engineering and math (STEM) majors in postsecondary institutions. Journal of Postsecondary Education and Disability, 27(3), 261-272.
Lin, N. (2001). Social capital: A theory of social structure and action. Cambridge University Press.

Lincoln, Y. S., \& Guba, E. G. (1985). Naturalistic inquiry. Sage.

Lombardi, A., Gerdes, H., \& Murray, C. (2011). Validating an assessment of individual actions, postsecondary, and social supports of college students with disabilities. Journal of Student Affairs Research and Practice, 48(1), 107126

Love, T. S., Kreiser, N., Camargo, E., Grubbs, M. E., Kim, E. J., Burge, P. L., \& Culver, S. M. (2014). STEM faculty experiences with students with disabilities at a land grant institution. Journal of Education and Training Studies, 3(1), 27-38.

Moon, N. W., Todd, R. L., Morton, D. L., \& Ivey, E. (2012). Accommodating students with disabilities in science, technology, engineering, and mathematics (STEM): Findings from research and practice for middle grades through university education. Atlanta: Center for Assistive Technology and Environmental Access, College of Architecture, Georgia Institute of Technology https:// hourofcode.com/files/accommodating-students-with-disabilities.pdf.

Morse, J. M. (1997). Perfectly healthy, but dead: The myth of inter-rater reliability. Qualitative Health Research, 7(4), 445-447.

National Science Foundation, National Center for Science and Engineering Statistics. (2019). Women, minorities, and persons with disabilities in science and engineering: 2019 (NSF Publication No. 19-304). National Science Foundation. https://www.nsf.gov/statistics/wmpd

Olson, J. D., McAllister, C., Grinnell, L. D., Gehrke Walters, K., \& Appunn, F. (2016). Applying constant comparative method with multiple investigators and inter-coder reliability. The Qualitative Report, 21(1), 26-42 https://nsuworks. nova.edu/tqr/vol21/iss $1 / 3$.

Peña, E. V. (2014). Marginalization of published scholarship on students with disabilities in higher education journals. Journal of College Student Development, 55(1), 30-40. https://doi.org/10.1353/csd.2014.0006.

Pham, A. V., \& Riviere, A. (2015). Specific learning disorders and ADHD: current issues in diagnosis across clinical and educational settings. Current Psychiatry Reports, 17(6), 38. https://doi.org/10.1007/s11920-015-0584-.

Raue, K., \& Lewis, L. (2011). Students with disabilities at degree-granting postsecondary institutions (NCES Publication No. 2011-018). U.S. Department of Education, National Center for Education Statistics. https://nces.ed.gov/ pubs2011/2011018.pdf

Reaser, A., Prevatt, F., Petscher, Y., \& Proctor, B. (2007). The learning and study strategies of college students with ADHD. Psychology in the Schools, 44(6), 627-638.

Richards, K. A. R., \& Hemphill, M. A. (2018). A practical guide to collaborative qualitative data analysis. Journal of Teaching in Physical Education, 37(2), 225231 https://doi.org/10.1123/ttpe.2017-0084.

Ryder, A. J., \& Mitchell, J. J. (2013). Measuring campus climate for personal and social responsibility. New Directions for Higher Education, 2013(164), 31-48.

Saldaña. (2015). The coding manual for qualitative researchers (3rd ed.). Sage.

Sandelowski, M., \& Barroso, J. (2003). Writing the proposal for a qualitative research methodology project. Qualitative Health Research, 13(6), 781-820. https://doi.org/10.1177/1049732303013006003.

Schreffler, J., Vasquez lii, E., Chini, J., \& James, W. (2019). Universal design for learning in postsecondary STEM education for students with disabilities: A systematic literature review. International Journal of STEM Education, 6(1), 8. https://doi.org/10.1186/s40594-019-0161-8.

Seidel, S. B., Reggi, A. L., Schinske, J. N., Burrus, L. W., \& Tanner, K. D. (2015), Beyond the biology: A systematic investigation of noncontent instructor talk in an introductory biology course. CBE Life Sciences Education, 14(4), ar43. https://doi.org/10.1187/cbe.15-03-0049.

Smith, T. E. (2001). Section 504, the ADA, and public schools: What educators need to know. Remedial and Special Education, 22(6), 335-343.

Stamp, L., Banerjee, M., \& Brown, F. C. (2014). Self-advocacy and perceptions of college readiness among students with ADHD. Journal of Postsecondary Education and Disability, 27(2), 139-160.

Stanton, J. D., Dye, K. M., \& Johnson, M. S. (2019). Knowledge of learning makes a difference: A comparison of metacognition in introductory and senior-level biology students. CBE Life Sciences Education, 18(2), ar24. https://doi.org/10. 1187/cbe.18-12-0239.

Taylor, S. S. (2005). Special education, private schools, and voucers: Do all students get choice? Journal of Law and Education, 34(1), 1-24 https://doi. org/10.1177/07419325050260050301.

Test, D. W., Fowler, C. H., Wood, W. M., Brewer, D. M., \& Eddy, S. (2005). A conceptual framework of self-advocacy for students with disabilities. 
Remedial and Special Education, 26(1), 43-54. https://doi.org/10.1177/ 07419325050260010601

Thurston, L. P., Shuman, C., Middendorf, B. J., \& Johnson, C. (2017). Postsecondary STEM education for students with disabilities: Lessons learned from a decade of NSF funding. Journal of Postsecondary Education and Disability, 30(1), 4960.

Timmerman, L. C., \& Mulvihill, T. M. (2015). Accommodations in the college setting: The perspectives of students living with disabilities. The Qualitative Report, 20(10), 1609-1625 https://nsuworks.nova.edu/tqr/vol20/iss10/5.

Tracy, S. J. (2010). Qualitative quality: Eight "big-tent" criteria for excellent qualitative research. Qualitative Inquiry, 16(10), 837-851. https://doi.org/10. $1177 / 1077800410383121$.

Vaccaro, A., Kimball, E. W., Wells, R. S., \& Ostiguy, B. J. (2015). Researching students with disabilities: The importance of critical perspectives. New Directions for Institutional Research, 2014(163), 25-41. https://doi.org/10.1002/ir.20084.

VERBI Software. (2017). MAXQDA 2020 [computer software]. Berlin: VERBI Software. maxqda.com

Walker, A. R., \& Test, D. W. (2011). Using a self-advocacy intervention on African American college students' ability to request academic accommodations. Learning Disabilities Research and Practice, 26(3), 134-144. https://doi.org/10. 1111/j.1540-5826.2011.00333.x.

Walker, H. M., Calkins, C., Wehmeyer, M. L., Walker, L., Bacon, A., Palmer, S. B., et al. (2011). A social-ecological approach to promote self-determination. Exceptionality, 19(1), 6-18. https://doi.org/10.1080/09362835.2011.537220.

Ward, M. J., \& Meyer, R. N. (1999). Self-determination for people with developmental disabilities and autism: Two self-advocates' perspectives. Focus on autism and other developmental disabilities, 14(3), 133-139.

Wehmeyer, M. L., Abery, B. H., Mithaug, D. E., \& Stancliffe, R. J. (2003). Theory in self-determination: Foundations for educational practice. Charles C Thomas.

Whitney, J., Langley-Turnbaugh, S., Lovewell, L., \& Moeller, B. (2012). Building relationships, sharing resources, and opening opportunities: A STEM learning community builds social capital for students with disabilities. Journal of Postsecondary Education and Disability, 25(2), 131-144.

Wolf, L. E. (2001). College students with ADHD and other hidden disabilities: Outcomes and interventions. Annals of the New York Academy of Sciences, 931(1), 385-395.

Yssel, N., Pak, N., \& Beilke, J. (2016). A door must be opened: Perceptions of students with disabilities in higher education. International Journal of Disability, Development and Education, 63(3), 384-394. https://doi.org/10.1080/ 1034912X.2015.1123232.

\section{Publisher's Note}

Springer Nature remains neutral with regard to jurisdictional claims in published maps and institutional affiliations.

\section{Submit your manuscript to a SpringerOpen ${ }^{\circ}$ journal and benefit from:}

- Convenient online submission

- Rigorous peer review

- Open access: articles freely available online

- High visibility within the field

- Retaining the copyright to your article

Submit your next manuscript at $\boldsymbol{\nabla}$ springeropen.com 